\title{
SALMAN RUŽDI I KANON ANGLO-INDIJSKE KNJIŽEVNOSTI
}

\author{
SRĐAN SIMONOVIĆ 1 \\ Univerzitet u Beogradu, \\ Filološki fakultet, \\ Beograd, Srbija
}

Rad sagledava promenu pozicije Salmana Ruždija tokom njegove spisateljske karijere, od istaknutog predstavnika postkolonijalne intervencije u odnosu na kanon engleske književnosti, početkom osamdesetih godina XX veka, preko njegovog ustoličenja kao popularnog, uticajnog i takoreći „kanonskog" pisca, pa sve do sporne uloge u kojoj se našao kao priređivač kontroverzne Vintidž antologije indijske književnosti 1947-1997. Detaljna analiza Ruždijevog predgovora ovoj antologiji, koji spada među njegove ključne nefikcionalne tekstove, usmerena je na autorove stavove 0 engleskom kao legitimnom jeziku indijske književnosti, kao i na Ruždijev pregled, ocenu i izbor pisaca uvrštenih u antologiju kojom on de fakto uspostavlja anglo-indijski kanon. Uz osvrt na neke od reakcija koje su usledile, kao što je kontra-antologija Amita Čaudurija, ali i preuzimanje Ruždijevog predgovora kao nove odrednice u Oksfordskom leksikonu engleske književnosti, u zaključku rada ukratko se razmatraju legitimizovani status engleskog kao jednog od jezika indijske književnosti u XXI veku, kao i konsolidacija anglo-indijske književnosti kao žive i samosvojne oblasti u okviru sve šireg polja književnosti na engleskom jeziku.

Ključne reči: Salman Ruždi, anglo-indijska književnost, postkolonijalna književnost, antologija, kanon, bum, jezičko pitanje u Indiji.

Među kritičarima i piscima danas je uglavnom opšteprihvaćeno gledište da su objavljivanje i veliki uspeh romana Deca ponoći Salmana Ruždija (Midnight's Children, Salman Rushdie) 1981. godine označili prekretnicu, pa i pravu „revoluciju” u britanskoj književnosti (Stevenson 2004: 5-6), a još više u indijskoj književnosti pisanoj na engleskom jeziku (Anjaria 2015: 4; Ashcroft 2013: 29; Chaudhuri 2001: 484; Desai 1995: vii-xi; Huggan 2001: 69; Joshi 2002: 229, 248; Sen/Roy 2013: 9).

U to vreme, Ruždi nastupa kao šampion postkolonijalne književnosti: bivši kolonizovani narodi svojom novom književnošću „uzvraćaju udarac” nekadašnjoj

1 Kontakt podaci (Email): knesim@gmail.com 
imperiji, prisvajajući jezik kolonizatora i koristeći ga za svoje specifične potrebe. Ruždi je o ovoj temi snažno progovorio u članku objavljenom u Tajmsu (The Times) 1982, „Imperija žestoko otpisuje” („The Empire Writes Back with a Vengeance”), čiji je naslov kasnije pozajmljen za jednu od prvih i najznačajnijih književno-kritičkih studija posvećenih postkolonijalnoj književnosti. ${ }^{2}$

Ruždi je u ovom članku konstatovao da je engleski jezik, kao književno sredstvo, postao „nezavisan ili denacionalizovan”, odnosno internacionalizovan: „Engleski, koji više nije samo jezik Engleske, sada raste iz mnogobrojnih korena; a njegovi nekadašnji kolonizovani subjekti odvajaju prostrane teritorije unutar jezika za sebe. Imperija uzvraća udarac" (Rushdie 1982a: 8). Ruždi ističe pozitivni primer američkih i irskih pisaca, koji su u prošlosti takođe morali da izvojuju slobode koje sada za sebe osvajaju pisci iz drugih bivših kolonija, ali i hvali fleksibilnost engleskog jezika zbog njegove sposobnosti da "obuhvati toliko različitih realnosti” (Rushdie 1982a: 8).

Značajno je da Ruždi već tada kao primer za ugled navodi i jednog prethodnika iz sopstvene, indijske tradicije, G. V. Desanija (G. V. Desani), autora komičnog romana Sve o H. Hateru (All about H. Hatterr) iz 1948. godine, koji je, kako Ruždi kaže, „pokazao kako engleski može da se rastegne i oblikuje dok ne progovori autentično indijskim glasom [...] Bio je to prvi veliki potez dekolonizujućeg pera" (Rushdie 1982a: 8).

Naravno, ova vrsta intervencija u odnosu na engleski jezik i kanon engleske književnosti nipošto nije bila nova. Još 1937. godine, anglo-indijski pisac Radža Rao (Raja Rao) izneo je slične zaključke u predgovoru za svoj roman Kantapura (Kanthapura) (Rao 1974: v-vi), a tokom šezdesetih i sedamdesetih godina afrički pisci iz zemalja koje su se osamostaljivale u procesu dekolonizacije ukazivali su na neophodnost da se stvori engleski koji bi bio univerzalan, ali bi ujedno prenosio i jedinstveno iskustvo afričkog čoveka (Achebe 1975: 61). ${ }^{3}$

Međutim, uspon Ruždijeve karijere se manje-više poklopio sa akademskim i teorijskim raspravama oko proširivanja kanona engleske i američke književnosti, ${ }^{4} \mathrm{kao} \mathrm{i}$ sausponom postkolonijalne kritikeiteorije. ${ }^{5}$ Kaopopularan pisacidobitniknajprestižnijih književnih nagrada, Ruždi je vremenom i sam stekao status „kanonskog” pisca, i to u tolikoj meri da se može slobodno reći da njegovo delo predstavlja ovaploćenje kanona anglo-indijske književnosti, ${ }^{6}$ ili u najmanju ruku zauzima centralno mesto u njemu.

Ruždi je pisac koji često ističe svoje kosmopolitske uzore i uticaje, uključujući i one indijske, ${ }^{7}$ kao neku vrstu ličnog književnog rodoslova (ili kanona), a 1997. godine pružila mu se prilika da i sasvim konkretno doprinese uspostavljanju kanona anglo-indijske

2 Ashcroft, Bill, Gareth Griffiths and Helen Tiffin. The Empire Writes Back: Theory and Practice in Post-Colonial Literatures. (1989) $2^{\text {nd }}$ edition. London: Routledge, 2002.

3 Ačebe je pri tome naglasio da afrički pisci nameravaju da „učine nečuvene stvari sa engleskim jezikom” (Achebe 1975: 7).

4 Ove rasprave sažeto rezimira Gorak 1991: 222-223.

5 Ulka Anđarija (Ulka Anjaria) skreće pažnju na činjenicu da su Deca ponoći objavljena samo dve godine posle uticajnog Saidovog Orijentalizma (Edward Said, Orientalism; Anjaria 14).

6 Naziv "anglo-indijska književnost” preuzet je, kao najpodesniji za naš jezik, iz Oksfordskog leksikona engleske književnosti (The Oxford Companion to English Literature, Birch 2009: 60-61). 0 upotrebi različitih naziva koji se koriste za ovaj pojam, v. Anjaria 26.

7 V. npr. Rushdie 1992:21, 276. Anki Mukerdži (Ankhi Mukherjee) napominje da Ruždi pravi „izbor po srodnosti” da bi svojim izborom pisaca definisao samoga sebe (Mukherjee 2014: 6). 
književnosti kada je, zajedno sa svojom tadašnjom suprugom Elizabet Vest (Elizabeth West), povodom pedesete godišnjice nezavisnosti indijske države priredio Vintidž antologiju indijske književnosti 1947-1997 (The Vintage Book of Indian Writing 19471997). Ova antologija obuhvata tekstove trideset dvoje autora, a pored samog Ruždija uključuje i Nehrua (Jawaharlal Nehru) ${ }^{8}$ i Ruždiju dragog filmskog reditelja Satjađita Reja (Satyajit Ray), koji i nisu pisci u pravom smislu te reči. Međutim, najkontroverzniji aspekt Ruždijevog izbora ogleda se u činjenici da je u antologiju uvršten samo jedan tekst koji nije izvorno napisan na engleskom. ${ }^{9}$ Objašnjenje dato u predgovoru glasi da se dobri prevodi sa indijskih jezika jedva mogu naći, a i da sam kvalitet dostupnih književnih dela nije zadovoljio kriterijume antologičara (Rushdie 2002: 147).

Isti tekst koji je poslužio kao predgovor za ovu antologiju objavljen je u leto 1997. i u tematskom broju američkog časopisa Njujorker (New Yorker) posvećenom novoj anglo-indijskoj književnosti, a kasnije je preštampan i u Ruždijevoj knjizi eseja Pređi ovu crtu (Step Across This Line: Collected Nonfiction 1992 - 2002). ${ }^{10}$ Rečje o jednom od ključnih, „programskih" nefikcionalnih tekstova ovog pisca, jer u njemu Ruždi definiše i brani svoje stavove o dva suštinska pitanja. To je, s jedne strane, njegova apologija pisanja na engleskom jeziku, u povremeno polemičkom tonu, zasnovana na istim načelima kao i članak napisan za Tajms petnaest godina ranije, a takođe i njegova ocena anglo-indijske književnosti, kojom se određuje njen kanon. Ruždi ovim tekstom praktično uspostavlja domaću tradiciju na koju se oslanja, budući da vrednuje prethodnu generaciju angloindijskih pisaca i daje povoljniju ocenu onima za koje smatra da su utrli put njegovim savremenicima, pa i njemu samom.

Prva polovina ovog eseja zapravo je rasprava o jeziku i književnosti indijskih pisaca koji stvaraju na engleskom. Ruždi razmatra kako i zašto oni to čine, kao i da li je reč 0 legitimnom izboru, s obzirom da je taj izbor često bio osporavan. Druga polovina sadrži kratki, ovlašni istorijski pregled anglo-indijske književnosti, sa naglaskom na razdoblju koje antologija pokriva.

Razmatrajući mesto i ulogu engleskog jezika u Indiji, Ruždi napominje da je nevolja u tome što se ovom jeziku zbog kolonijalne prošlosti još uvek osporava autentičnost, te da će indijska književnost pisana na njemu za pojedine kritičare izgleda zauvek ostati „postkolonijalna anomalija” i „kopile Imperije” (Rushdie 2002: 148). Nasuprot tome, Ruždi se protivi stavu da engleski jezik u Indiji mora nužno ostati obeležen kao tuđinski samo zato što je stigao u zemlju odnekud spolja: „I moj sopstveni maternji jezik, urdu, logorski žargon ranijih, muslimanskih osvajača Indije, takođe je bio jezik imigranata, iskovan od mešavine uvezenog jezika osvajača i lokalnih jezika koje su oni tamo zatekli. Međutim, on je odavno postao naturalizovani jezik potkontinenta, a

8 Reč je o tekstu "Susret sa sudbinom" („Tryst with Destiny”), Nehruovom govoru održanom prilikom proglašenja nezavisnosti Indije, kojim se antologija otvara (Rushdie/West 1997: 1-2, a koji Ruždi inače citira i u romanu Deca ponoći. V. Rushdie 1982b: 115-116, u prevodu Rušdi 1987: 148-151).

9 U pitanju je Saadat Hasan Manto, "Toba Tek Singh" (Rushdie/West 1997: 24-31), prevod sa urdua.

10 Ovde se uglavnom držimo te najkasnije redakcije ovog teksta, a na značajne razlike između njegove tri postojeće verzije ukazujemo u daljoj analizi. Kod nas je ovaj tekst delimično preveden i objavljen pod naslovom „Pregled indijske književnosti” (Rušdi 2000) u antologiji Savremena indijska priča koju je prevela i priredila Nadežda Obradović. Nažalost, neki delovi Ruždijevog teksta su iz neobjašnjivih razloga izostavljeni, a pošto je i sam prevod delimično nepouzdan, na njega se oslanjamo samo mestimično. 
sada se to desilo i sa engleskim. Engleski je postao indijski jezik" (Rushdie 2002: 149). Štaviše, dodaje Ruždi, to što je engleski, kao i urdu, nekadašnji kolonijalni jezik znači da on u Indiji nije ograničen na određeno geografsko područje, zbog čega je za mnoge Indijce neutralniji u kulturnom smislu od većine lokalnih jezika, pa i od hindija, jezika etničke većine (Rushdie 2002: 149).

U svakom slučaju, Ruždi ponavlja svoj zaključak iz članka u Tajmsu da je indijski engleski sasvim samosvojan i različit od britanskog engleskog, dok se uspeh angloindijskih pisaca ogleda upravo u tome što su pronašli osobene indijske glasove, baš kao i pisci iz drugih bivših kolonija pre njih (Rushdie 2002: 149).

Međutim, Ruždi ukazuje i na to da su zamerke i optužbe koje se ovim piscima upućuju brojne i da ne prestaju. Tako se tvrdi da oni uglavnom dolaze iz dobrostojeće klase i žive u inostranstvu, što ih ograničava u izboru tema; da su popularniji van Indije nego u zemlji; da ih zapadnjačka izdavačka industrija forsira da bi nametnula svoje standarde i na Istoku; da su bez korena i da više ne razumeju situaciju u Indiji; kao i da listom pate od „ružditisa” (Rushdie 2002: 149-150). Ruždi smatra da je većina ovih kritika u stvari ideološke prirode i da se ne odnosi na književne vrednosti nego na klasu, moć i uverenja. Istina je, prihvata Ruždi, da je engleski jezik moćan, baš kao i izdavačka industrija. Ali, iako se nekim indijskim kritičarima možda čini da im se nekakav kanon nameće spolja, na Zapadu je utisak drugačiji - da se pojavila uzbudljiva nova generacija pisaca koji dolaze iz Indije i kojima je pošlo za rukom da se nametnu Zapadu. Ne bi li onda, pita se Ruždi, trebalo da smo zadovoljni što je tako i da slavimo uspeh književnih dela u kojima je ostvareno zavidno majstorstvo na engleskom jeziku? (Rushdie 2002: 150-151)

Obrazlažući svoj izbor pisaca obuhvaćenih antologijom, Ruždi iznosi i kontroverznu ocenu da „i fikcionalni i nefikcionalni prozni tekstovi indijskih pisaca koji stvaraju na engleskom, napisani u ovom razdoblju, čine solidniji i značajniji korpus dela od većine onoga što je $u$ istom periodu stvoreno na osamnaest "priznatih" indijskih jezika, takozvanih „vernakulara"'” (Rushdie 2002: 146).

U verziji istog ovog teksta objavljenoj u Njujorkeru, navedena rečenica nastavlja se, posle tačke i zapete, sledećom tvrdnjom: „, [...] i zaista, ova nova, tek propupela angloindijska književnost predstavlja možda najvredniji doprinos koji je Indija do sada dala svetu knjiga. Prava indijska književnost iz prvih pola veka postkolonijalnog razdoblja napisana je na jeziku koji su Britanci ostavili za sobom". (Rushdie 1997: 50).

Nije slučajno da je Ruždi izostavio ovaj odlomak iz kasnije verzije svog teksta, jer on podrazumeva i da su dela njegovih savremenika (pa i njegova sopstvena) vredniji „doprinos svetu knjiga” od klasičnih indijskih epova i celokupne hiljadugodišnje književne tradicije indijskog potkontinenta. Takođe, u verziji teksta objavljenoj kao uvod u antologiju, a i u kasnijoj zbirci eseja, postoji i pasus u kome se ovaj stav ublažava izričitom tvrdnjom da se autorova teza odnosi samo na prozu, jer anglo-indijski pesnici, uz nekoliko izuzetaka, ne dostižu nivo svojih kolega prozaista (Rushdie 2002: 147). To dodatno objašnjenje ukazuje da je Ruždi verovatno imao na umu isključivo modernu prozu, i to prvenstveno roman kao noviju književnu formu koja je u Indiju „uvezena" sa Zapada u XIX veku, zajedno sa engleskim jezikom (Joshi 2002: 8, 17).

Navodeći da je i njega samog iznenadilo što je, pripremajući antologiju, došao do ovakvog zaključka, koji je po njegovom mišljenju i duboko ironičan budući da je 
engleski jezik nekadašnjih kolonizatora, Ruždi skreće pažnju na to da je njegov tekst po prvobitnom objavljivanju izazvao bučne proteste i osude (Rushdie 2002: 147, fusnota), ali napominje da ipak ostaje pri svom stavu. Dodatna ublažavanja izneta su u konstatacijama da je u sto godina pre sticanja nezavisnosti bilo mnogo pisaca na indijskim jezicima koji bi zaslužili mesto u antologiji, kao i da se podrazumeva da među indijskim piscima koji ne pišu na engleskom ima izuzetnih stvaralaca (pa Ruždi nekolicinu takvih i nabraja). Međutim, kako Ruždi napominje, upravo je koncentracija novih talenata među anglofonim piscima izazvala fenomen - „bum” nove angloindijske književnosti (Rushdie 2002: 146-147). ${ }^{11}$

Ruždi zaključuje da su kritike upućene piscima koji su postigli međunarodni uspeh samo izraz provincijalizma, inače možda najveće mane indijske književnosti na vernakularnim jezicima (Rushdie 2002: 151), a da između književnosti na engleskom i na drugim indijskim jezicima ne bi trebalo da postoji neprijateljstvo: „Na kome god jeziku da pišemo, svi pijemo sa istog izvora. Sve nas hrani Indija, taj neiscrpni rog izobilja" (Rushdie 2002: 152).

U pregledu istorije anglo-indijske književnosti, Ruždi tek notira pojavu prvog, neuspelog, romana na engleskom, 1864. godine, da bi odmah zatim konstatovao da u sledećih sedamdesetak godina na engleskom nije bilo kvalitetne proze. Utemeljivači nove anglo-indijske tradicije pripadali su, po Ruždijevom mišljenju, Nehruovoj generaciji, a među njima, osim samog Nehrua, on izdvaja nekoliko pisaca, ponekad uz izvesne ograde: Mulk Radž Anand (Mulk Raj Anand) je bio dosledni socrealista, a Radža Rao danas zvuči zastarelo, „u isti mah visokoparan i arhaičan” (Rushdie 2002: 153). Dvojica velikih pisaca kojima je posvećeno nešto više pažnje jesu R. K. Narajan (R. K. Narayan) i G. V. Desani. Dok je Narajan svetski poznat pisac, autor niza romana, koji svojim blagim i lako humorističkim stilom uspeva da prodre u samu srž tradicionalnog indijskog života, Ruždiju je draži zanemareni Desani, pisac samo jednog romana koji, međutim, predstavlja „prvi istinski napor da se prevaziđe engleština engleskog jezika” (Rushdie 2002: 153). Rezultat je „zapanjujuća, zbunjujuća, razigrana proza” od koje je i sam Ruždi imao šta da nauči (Rušdi 2000: 16). Pozivajući se na sud Milana Kundere (Milan Kundera) da "sva moderna književnost potiče ili od Ričardsonove Klarise (Samuel Richardson, Clarissa) ili od Sternovog Tristrama Šendija (Laurence Sterne, Tristram Shandy) ", Ruždi zaključuje da ako je, po analogiji, Narajan neka vrsta indijskog Ričardsona, onda je Desani njegov „Šendijevski drugi" (Rushdie 2002: 153). Ruždi zatim navodi i dva odlomka kojima ilustruje Desanijev osobeni stil, a iz jednog od njih je,

11 Pojam „buma” poznat je u književnom kontekstu iz vremena takozvanog „buma” latinoameričke književnosti, prvenstveno romana, tokom šezdesetih i sedamdesetih godina XX veka. V. odrednicu „Boom, the", Birch 2009: 144; za kratak istorijski pregled sa osvrtom na najznačajnije predstavnike, v. King 2005: 59-80; u literaturi na našem jeziku, Prens i Golobof (Prenz/Goloboff) daju izrazito socijalističko tumačenje ovog fenomena (Prens/Golobof 1982: 267-286). Možda najbolji izvor predstavlja informativna i lako čitljiva lična perspektiva koju velikan čileanske književnosti Hose Donoso nudi u svojoj autobiografskoj knjižici Lična istorija buma (José Donoso, Historia personal del „boom", 1972). Donoso upozorava da je sam termin „bum”, koji je nemoguće definisati, „proizvod histerije, zavisti i paranoje” (Donoso 1987: 9), i da, uostalom, u engleskom ova reč uopšte nije neutralna, već da ima negativne konotacije nečeg kratkotrajnog, lažnog i šupljeg, a da su u kontekstu latinoameričke književnosti neprijateljski nastrojeni kritičari usvojili taj naziv i zapravo ga preneli iz sfere književnosti u sferu publiciteta i medija (Donoso 1987: 10-13). Sve je ovo itekako relevantno i za bum anglo-indijske književnosti. 
kako se ispostavlja, preuzeo i naslov svog teksta, „Takva ti je, majkoviću, ta orijentalna scena!" („Damme, This Is the Oriental Scene for You!") (Rushdie 2002: 154).

U nastavku teksta, Ruždi razmatra novije pisce. Ponekome je posvećen po jedan pasus, kao u slučaju Rut Prauer Džabvale (Ruth Prawer Jhabvala) i Anite Desaj (Anita Desai). Najpolu (V. S. Naipaul), za koga kaže da nijedan pregled moderne indijske književnosti ne bi bio potpun bez njega, dato je više prostora nego ijednom drugom piscu, što je donekle paradoksalno s obzirom da je Najpol odbio da bude uvršten u antologiju (Rushdie/West 1997: xix). Ruždi uglavnom raspravlja o tome kako namćorasti Najpol, koji tehnički govoreći i nije iz Indije, doživljava zemlju svojih predaka, te opovrgava njegov negativni sud o indijskoj književnosti (Rushdie 2002: 155-157).

Osamdesetih i devedesetih godina, odnosno u Ruždijevoj sopstvenoj generaciji, došlo je, kako on napominje, do prave poplave dobrih pisaca, koje Ruždi praktično samo nabraja, a među kojima su Rohinton Mistri (Rohinton Mistry), Vikram Set (Vikram Seth), Vikram Čandra (Vikram Chandra), Amitav Goš (Amitav Ghosh), Sara Suleri (Sara Suleri) i Amit Čauduri (Amit Chaudhuri) (Rushdie 2002: 157). Uglavnom se u po jednoj rečenici skiciraju osnovne odlike ovih pisaca i navodi njihovo najpoznatije delo. U optimističkom tonu, Ruždi zatim konstatuje da se pojavljuje i nova generacija talentovanih pisaca, mlađa od njegove, među kojima navodi Arundati Roj (Arundhati Roy), Kiran Desaj (Kiran Desai) i Ardašira Vakila (Ardashir Vakil), uz zaključak da je ovaj trend dokaz da „iz susreta Indije sa engleskim jezikom [...] nastavljaju da se rađaju nova deca, obdarena raskošnim darovima" (Rushdie 2002: 158).

Tekst se završava vrlo upečatljivom slikom:

Mapa sveta, u standardnoj Merkatorovoj projekciji, nije fer prema Indiji, koju prikazuje kao znatno manju od, recimo, Grenlanda. I na mapi svetske književnosti Indija je isuviše dugo bila umanjena. Međutim, danas, pedeset godina posle proglašenja nezavisnosti Indije, to doba anonimnosti je na izmaku. Indijski pisci pocepali su staru mapu i ubrzano iscrtavaju svoju sopstvenu (Rushdie 2002: 158).

Ako su kritičari za Ruždija rado tvrdili da je romanom Deca ponoći uneo indijsku književnost na mapu sveta (npr. Brennan 1989: 80), Ruždi sada koristi istu tu metaforu $u$ korist cele nove generacije pisaca. A rušenje starog i izgradnja nečeg novog inače je slika koju Ruždi često ponavlja kada govori o ulozi književnosti (i umetnosti uopšte). ${ }^{12}$

Po objavljivanju Ruždijeve antologije i tematskog broja Njujorkera, usledile su brojne negativne reakcije, prvenstveno $u$ Indiji, u kojima se uglavnom ukazivalo na bogatstvo i značaj književnosti na vernakularnim jezicima. ${ }^{13}$ Zamerka koja verovatno ima najviše smisla takoreći je tehnička, a glasi da je antologiju možda trebalo koncipirati kao pregled indijske književnosti na engleskom jeziku a ne indijske književnosti uopšte (Shankar 2012: 18; Tejpal 1997: n. pag.).

Možda najupečatljiviji, a svakako najobimniji odgovor na Ruždijevu antologiju stigao je nekoliko godina kasnije u vidu kontra-antologije koju je sastavio anglo-indijski

12 Npr. u esejima o Ginteru Grasu (Günter Grass) i posleratnoj generaciji nemačkih pisaca ("Günter Grass", Rushdie 1992: 279) ili o filmu Brazil Terija Gilijama (Terry Gilliam; „The Location of Brazil", Rushdie 1992: 122-123).

13 Neke od ovih reakcija u sažetom obliku navodi Huggan 2001: 63-64. V. takođe Tejpal 1997: n. pag. 
pisac Amit Čauduri (The Picador Book of Modern Indian Literature, 2001). Iako tvrdi da njegova knjiga „nije odgovor na bilo koju drugu antologiju” (Chaudhuri 2001: xxxiii), kada se u predgovoru pita zar indijsku književnost može da predstavlja samo „šačica pisaca koji stvaraju na engleskom, žive u Engleskoj ili Americi, i koje je čovek možda sreo na nekom partiju, a od kojih je većina objavila samo dva romana, neki čak samo jedan" (Chaudhuri 2001: xvii), aluzija na raniju Ruždijevu antologiju je sasvim jasna. Čauduri zatim dodaje da je to isto kao kada bismo o celokupnoj engleskoj književnosti sudili samo na osnovu dela nekolicine savremenih romanopisaca kao što su Džulijan Barns (Julian Barnes), Martin Ejmis (Martin Amis) i Andžela Karter (Angela Carter). Ipak, kako on kaže, upravo tako se, po logici izdavačke industrije i marketinga, u medijima i anglosaksonskoj akademskoj kritici zanemaruju dela na vernakularima, a celokupna indijska književnost izjednačava se sa onom pisanom na engleskom, dok je čak i retko ko od samih anglo-indijskih pisaca uveren da je deo nekakvog „buma” (Chaudhuri 2001: xvii). Čauduri se takođe sa nevericom pita da li neko zaista misli da se i ostvarenja ovih autora mogu objektivno sagledati nezavisno od prethodne indijske intelektualne i književne tradicije (Chaudhuri 2001: xvii). ${ }^{14}$

Čauduri smatra i da je status engleskog jezika u Indiji još uvek dvosmislen, čak i ako je ovaj jezik neizbežan, dok tvrdnja da je on danas postao indijski jezik zahteva niz kvalifikacija, jer, kako Čauduri naglašava, „engleski nije jezik Indije na isti način kao što je jezik Amerike, niti je indijski na isti način na koji su bengalski ili urdu indijski jezici. Položaj i značenje engleskog u Indiji tek treba da postanu jasni; sve je to još uvek deo procesa koji je daleko od završenog" (Chaudhuri 2001: xxii).

Pikador antologija, za koju Čauduri kaže da "nije reprezentativna” (Chaudhuri2001: xxxii), nešto je obimnija od one Ruždijeve i obuhvata trideset osam pisaca, od kojih se neki preklapaju sa Ruždijevim izborom, pri čemu ni sam Ruždi nije izostavljen. Kao odgovor na tvrdnju da nema dovoljno dobrih prevoda sa indijskih vernakulara, Čauduri je neke od prevoda obezbedio specijalno za svoju antologiju ( $\mathrm{i}$ lično, sa bengalskog). Interesantno je da je odnos engleskog i drugih jezika i ovde otprilike pola-pola, tako da je engleski opet u ukupnoj prednosti, dok od vernakulara apsolutno dominira bengalski, inače Čaudurijev maternji jezik.

I u slučaju ove, po našem sudu inače lepe antologije, reakcije su bile izmešane..$^{15}$

S obzirom na kontroverze koje je Ruždi izazvao Vintidž antologijom i svojim predgovorom, zanimljivo je da je nedugo potom angažovan kao saradnik uglednog i autoritativnog Oksfordskog leksikona engleske književnosti (Drabble 2000: ix), u čijem je šestom izdanju iz 2000. godine baš ovaj esej, u sažetoj verziji, upotrebljen za novouvedenu odrednicu „Anglo-indijska književnost” („Anglo-Indian literature”, Drabble 2000: 29). Mada u pomenutom izdanju Oksfordskog leksikona nije precizirano koje je odrednice svako od saradnika sastavio, na osnovu prostog upoređivanja nameće se zaključak da je upravo Ruždi autor navedene odrednice, budući da ona u glavnim obrisima ponavlja njegov tekst iz Njujorkera i Vintidž antologije, sa

14 Činjenica je da nam još uvek nedostaju studije koje bi ponudile temeljnu analizu odnosa sa tom konkretnom tradicijom, pogotovu kad je reč o Ruždijevom delu. Redak izuzetak u tom smislu je odlična knjiga Prije Đoši (Priya Joshi 2002).

15 Za dve oprečne ocene Čaudurijeve antologije v. Karnad 2001: n. pag. i Gandhi 2001: n. pag, oba na: http:// www.thehindu.com/2001/08/19/stories/1319067g.htm 
istom argumentacijom, istim izborom pisaca i uz neke doslovno iste formulacije. U aktuelnom, sedmom izdanju Oksfordskog leksikona, iz 2009. godine, kao autorka iste, ali sada revidirane odrednice („Anglo-Indian literature”, Birch 2009: 60-61) navedena je Eleke Bomer (Elleke Boehmer; Birch 2009: 1151). Međutim, pažljivim čitanjem lako je utvrditi da je ugledna oksfordska profesorka postkolonijalne književnosti, donekle preradivši ovu odrednicu i dodavši joj uvodni deo, koji sada čini otprilike prvu polovinu teksta, ujedno u drugoj polovini ipak zadržala glavninu Ruždijevog pregleda angloindijske književnosti: od trideset dvoje pisaca iz Vintidž antologije, ovde ih se pominje dvadeset pet, a od autora koje Ruždi ne pominje dodato je samo pet pesnika iz XIX veka (u uvodnom delu odrednice), kao i jedna savremena spisateljka. Ruždijev izbor autora time ne samo da je priznat kao reprezentativan, već je njegovim zadržavanjem u ovakvoj publikaciji načinjen veliki korak dalje u tome da mu se prida takoreći "kanonski" status.

U zaključku možemo reći da je od vremena objavljivanja Vintidž antologije angloindijska književnost nesumnjivo stekla legitimitet i zasluženo mesto u okviru sve šireg polja književnosti na engleskom jeziku, o čemu, između ostalog, ubedljivo svedoči i uključivanje odrednice posvećene ovoj oblasti u Oksfordski leksikon. U međuvremenu su se pojavili brojni novi anglo-indijski pisci koji objavljuju knjige u velikim tiražima i stiču najuglednija književna priznanja, ${ }_{1}^{16}$ a jedan od utemeljivača postkolonijalnih studija, Bil Ěskroft (Bill Ashcroft), čak smatra da je u poslednjih tridesetak godina indijska dijaspora imala većeg uticaja na englesku književnost od bilo koje druge pojedinačne nacije (Ashcroft 2013: 29).

Situacija se izgleda izmenila i u pogledu položaja engleskog jezika u Indiji. U jednoj skorašnjoj studiji ističe se da je „engleski izgubio dobar deo nekadašnjeg ideološkog bagaža kao kolonijalni i uvezeni jezik, budući da ga omladina u urbanoj Indiji koja teži boljem životu sada smatra neophodnim sredstvom za iskorišćavanje globalnih mogućnosti" (Sen/Roy 2013: 13). Engleski je praktično postao još jedan od indijskih vernakulara, između ostalog i zahvaljujući tome što je odomaćen preko književnosti, i to prvenstveno romana (Joshi 2002: 229-230; Mukherjee 2014: 156). ${ }^{17}$ I odnos engleskog i drugih jezika u indijskim književnostima se menja, pa je i sve više anglo-indijskih autora koji su okrenuti domaćem indijskom, a ne međunarodnom tržištu (Anjaria 2015: 10-12)

S druge strane, ako je postkolonijalna književnost kao akademska disciplina (i tržišna kategorija izdavačke industrije) nepravedno zanemarivala književnost vernakulara, čini se da i na tom polju dolazi do pomaka, jer se i oblast postkolonijalne književnosti sve više preispituje i preobražava u transkulturne studija (Anjaria 2015: 1420; Mukherjee 2014: 18-22; Sen/Roy 2013: 14; Shulze-Engler 2009: x).

Posmatrano sa strane, iz naše specifične srpske perspektive, možemo zaključiti da je i nekadašnje kontroverze i polemike, kao i najnoviji razvoj teorijsko-kritičkih promišljanja, najbolje pre svega shvatiti kao podsticaj za dalje prevođenje i upoznavanje raznovrsnog i bogatog sveta savremene indijske književnosti, makar one na engleskom ako već ne i na vernakularnim jezicima.

16 Kao što su npr. Džumpa Lahiri (Jhumpa Lahiri) i Aravind Adiga (Aravind Adiga).

17 Mukerdži smatra da engleski danas u stvari funkcioniše kao "globalni vernakular" (Mukherjee 2014: 34, 113). 


\section{LITERATURA}

Achebe, C. 1975. Morning Yet on Creation Day. London: Heinemann.

Anjaria, U. 2015. A History of the Indian Novel in English. New York: Cambridge University Press.

Ashcroft, Bill. 2013. „Re-writing India." U K. Sen and R. Roy (eds.) Writing India Anew: Indian English Fiction 2000-2010. Amsterdam: Amsterdam University Press, 29-46.

Birch, D. (ed.) 2009. The Oxford Companion to English Literature. $7^{\text {th }}$ edition. Oxford: Oxford University Press.

Brennan, T. 1989. Salman Rushdie and the Third World: Myths of the Nation. Houndmills: Macmillan.

Chaudhuri, Amit (ed.) 2001. The Picador Book of Modern Indian Literature. London: Picador.

Desai, A. 1995. „Introduction.” U S. Rushdie, Midnight's Children. New York: Knopf, vii-xxi. Donoso, J. 1987. Historia personal del „boom”. (1972) Santiago de Chile: Andres Bello.

Drabble, M. (ed.) 2000. The Oxford Companion to English Literature. $6^{\text {th }}$ edition. Oxford: Oxford University Press.

Gandhi, L. 2001. „A Major Literary Event.” The Hindu, 19 August 2001. [Internet]. Dostupno na: http://www.thehindu.com/2001/08/19/stories/1319067g.htm [22.11.2015].

Gorak, J. 1991. The Making of the Modern Canon: Genesis and Crisis of a Literary Idea. London: Athlone.

Huggan, G. 2001. The Postcolonial Exotic: Marketing the Margins. London and New York: Routledge.

Joshi, P. 2002. In Another Country: Colonialism, Culture, and the English Novel in India. New York: Columbia University Press.

Karnad, G. 2001. „Squandered Opportunity.” The Hindu, 19 August 2001.[Internet]. Dostupno na: http://www.thehindu.com/2001/08/19/stories/1319067g.htm [22.11.2015].

King, J. 2005. „The Boom of the Latin American Novel.” U E. Krístal (ed.) The Cambridge Companion to the Latin American Novel. Cambridge: Cambrdige University Press, 59-80.

Mukherjee, A. 2014. What Is a Classic? Postcolonial Rewriting and Invention of the Canon. Stanford, CA: Stanford University Press.

Prens, H. 0. i H. M. Golobof. 1982. Istorija hispanoameričke književnosti. Prev. M. Josimčević. Beograd: Prosveta, et al.

Rao, R. 1974. Kanthapura. (1937) $2^{\text {nd }}$ edition. Madras: Oxford University Press.

Rushdie, S. 1997. „Damme, This Is the Oriental Scene for You!” New Yorker, 23-30 June 1997, 50-61.

Rushdie, S. 1982a. „The Empire Writes Back with a Vengeance.” Times, 3 July 1982: 8.

Rushdie, S. 1992. Imaginary Homelands: Essays and Criticism 1981 - 1991. (1991) London: Granta/Penguin.

Rushdie, S. 1982b. Midnight's Children. (1981) London: Book Club Associates.

Rushdie, S. 2002. Step Across This Line: Collected Nonfiction 1992 - 2002. New York: Random House.

Rushdie, S. and E. West (eds.) 1997. The Vintage Book of Indian Writing 1947-1997. London: Vintage. 
Rušdi, S. 1987. Deca ponoći. Prev. S. Koljević i Z. Mutić. Drugo izdanje. Beograd: BIGZ.

Rušdi, S. 2000. „Pregled indijske književnosti”. Prev. N. Obradović. U Obradović, N. (prir. i prev.) Savremena indijska priča. Beograd: Clio, 5-21.

Sen, K. and R. Roy (eds.) 2013. Writing India Anew: Indian English Fiction 2000-2010. Amsterdam: Amsterdam University Press.

Shankar, S. 2012. Flesh and Fish Blood: Postcolonialism, Translation, and the Vernacular. Berkeley: University of California Press.

Shulze-Engler, F. and S. Helff (eds.) 2009. Transcultural English Studies: Theories, Fictions, Realities. Amsterdam and New York: Rodopi.

Stevenson, R. 2004. The Oxford English Literary History, Vol. 12, 1960-2000: The Last of England? Oxford: Oxford University Press.

Tejpal, Tarun. 1997. „Rushdie and the Sea of Prejudice.” Outlook India, 16 July 1997 [Internet]. Dostupno na: http://www.outlookindia.com/article/rushdie-and-thesea-of-prejudice/203839 [22.11.2015].

\section{SUMMARY}

\section{SALMAN RUSHDIE AND THE ANGLO-INDIAN LITERARY CANON}

The paper discusses Salman Rushdie's development from one of the champions of the emerging postcolonial literature in the early 1980s, through his ascendancy within the literary establishment, to his doubtful status as arbiter of Anglo-Indian literature in his role as co-editor of the controversial Vintage Book of Indian Writing 1947-1997. Rushdie's introduction to this anthology is examined in detail as one of his key non-fictional texts, with a focus on his treatment of the language issue in Indian literature(s) and his version of the Anglo-Indian canon. After revisiting some of the reactions that followed the book's publication, notably Amit Chaudhuri's Picador Book of Modern Indian Literature (2001) and Rushdie's commission as a contributor to the Oxford Companion to English Literature, the paper concludes with a brief consideration of the current, legitimised status of English in Indian writing and the consolidation of Anglo-Indian literature as a well-established area within the ever expanding field of English studies.

KEYWORDS: Salman Rushdie, Anglo-Indian literature, postcolonial literature, anthology, canon, boom, laguage issue in India.

(Originalni naučni rad primljen 24.01.2016;

ispravljen 1.3.2016;

prihvaćen 9.3.2016) 